\title{
Review of David C. Colander's The making of an economist, redux. Princeton: Princeton University Press, 2007, 268 pp.
}

\author{
RENÉ L. P. MAHIEU \\ EIPE, Erasmus University Rotterdam
}

With The making of an economist, redux (henceforth: Redux), David Colander is building on his successful earlier work with Arjo Klamer: The making of an economist (1990). Redux has basically the exact same format as the earlier work. It is meant to be interesting for a very broad public: economists, (prospective) students of economics, and lay persons (Colander 2007, vii). In this review, I will give a short overview of the content of the book. Moreover, I will question how much extra value this new edition has over the old one, especially with an eye to people interested in the methodology and philosophy of economics.

The main body is the presentation of a survey done by Colander. Students of economics at top American graduate schools were asked to fill in questionnaires and some of them were interviewed so as to get a view of what graduate training is like from the perspective of the students. The main motivation behind this effort is that looking at graduate economics education would give insight into the profession as it stands, and into the changes that might be forthcoming. The content of the book is divided into three parts.

In the first part, the results from the survey are presented along with an example of the questionnaire that was used. Colander makes an effort to give us a profile of the students: what they are interested in, what their political orientation is, and what they think about their training. In all cases an effort is made to find interesting differences between the different schools. First, the quantitative data are analysed. This includes data like the age of the students and the number of foreign students, but also how students assess the relevance of neoclassical economics and the importance of a broad knowledge of the economics literature. To compensate for the limiting nature of questions needed to produce quantitative data, room for written comments on answers and open questions were also part of the questionnaire; these are discussed in the following chapter. Questions that were presented include "Do you see economics as relevant?" with answers like "Yes, 
economists are the only careful, structured, empirical thinkers on most economic, political and social topics" or "Uncertain. While not true to everyone, many economists undervalue the contributions of other disciplines and don't effectively engage in the policy-making process" or "No, normal people solve crosswords; economists write papers (of which 80 percent are never read)". And "What makes a successful economist?" with answers like "Well-published, often talked about, cited, invited to conferences; thinking of new things, happy" or "Curious, rigorous analytically, resourceful, relevant, creative" or "One who gets tenure (I do not interpret 'successful' necessarily to mean 'good')". Finally the results of a study of some of the respondents from the earlier survey are presented.

Colander's new general conclusion is that, contrary to his conclusion in the previous book, there is not much wrong with the education system; students are quite happy with the education that they receive. Overall this first part of Redux is a fairly interesting read, since it lives up to the goal of giving the reader some insight into the making of economists. But, it also suffers from problems inherent to the method employed. Colander cannot escape from ending up with many sentences in the following style: "Chicago had the greatest interest in... (x percent); MIT had the least (y percent). MIT had the most interest in... (x percent); Yale had the least (y percent), etcetera, etcetera". As a scientific endeavour, the use of questionnaires might also raise some eyebrows, especially among economists. This is acknowledged by Colander but he makes a strong case for granting the results some value nonetheless.

In fact, in the second part a transcription is given from the conversations Colander held with students, partly as a remedy against the problems inherent in the method. These conversations are presented without any further explicit comment. Although there are many interesting and entertaining things to be found in these dialogues, it does get quite repetitive.

In the third part reflections are given on the overall results, not only by David Colander, but also by Arjo Klamer, Colander's co-author in the previous 1990 book, and Robert M. Solow. Colander's main conclusion is that current graduate training has its problems, but overall is doing quite well. According to him, it has improved since the 80 s by becoming more focused on empirical research, and although there is still a strong focus on mathematics, it has become much more focused on application and less on purely mathematical exercises. The main remaining problem 
is that although economics has supposedly become a more diverse field, the core of graduate programmes has not changed accordingly.

Solow's reflection is mainly a defence of macroeconomics in reaction to a proposal, that Colander makes in part one, that the theoretic macroeconomics course should be taken out of the core of graduate programmes.

Klamer's reflection entitled 'Does this have to be our future?' is the most critical. For him the results show nothing remarkable; indeed a bit more attention is given to empirical work, but this has not solved the main problems within economics education. If anything, things have gotten worse. Differences between schools have gotten smaller, heterodox economics seems to have completely disappeared from the curriculum and so has the history of economics. This, together with an ever decreasing focus on the classical economics literature (Smith, Hayek, Keynes, Marx, and so forth) and on philosophy of science makes economics a less intellectual field than it could and should be.

It is in this final part that things should have been getting really interesting. But, sadly enough the book never achieves the apotheosis I was hoping for. Colander's own reflections are of some interest but they do not convey any sense of need or urgency, and more problematically they do not seem to be built on a clear (methodological) perspective of what graduate training should look like. This could be surprising for those readers who are familiar with Klamer and Colander's 1990 book in which Colander argued for what he called a "sociological approach to methodology" (Klamer and Colander 1990, 191). From that perspective graduate training was found to be defective in several ways, and these deficiencies ultimately came from problems within the science of economics in general. The main problem identified then was that the mainstream positivist methodology was focused on the formal empirical testing of hypotheses, while in economics at that time no generally accepted way of formal testing or other non-formal process for the selection of hypotheses could be found (Klamer and Colander 1990, 189-190). Therefore-Colander argued in 1990-new non-formalist methodological conventions should be established to guide economists and their students in their scientific enquiry.

Starting from this point of view, one would expect that, since Colander finds-in Redux - that existing problems have largely been solved, these new methodological conventions have indeed been found. Education must have become more focused on different formal and non- 
formal ways of discovering truth. However, in Redux, Colander is not at all concerned with making such a point. On the contrary, teaching the judgment and wisdom that should guide empirical testing are still not basic elements of graduate training. Nevertheless, Colander argues in Redux that new ways of doing formal empirical testing, that are appropriate in all or most cases, have been found. Furthermore Colander suggests that there has been a move to "a more inductive approach in which empirical evidence rather than theory guides research" (Colander 2007, 244). While something of course can be said for the positive developments of empirical methods in economics over the last twenty or so years, no constructive elaboration is made in that direction in Redux. Given the proliferation of books and journals such as EJPE, it is clear that questions concerning the methodology of economics have not been solved over the past 20 years. Especially from someone who in the past has shown interest in the more delicate questions of philosophy and methodology of economics, I was expecting a more thorough argumentation for a claim announcing that (almost) all is now well in economic science.

Taking these criticisms into account, this book is still a must-read especially for two groups of people. First, those who are contemplating going into graduate training in economics would be helped to get a clearer picture of what such graduate training will actually be like. This is all the more important since in the book it is argued convincingly that there is a big gap between what students expect to learn and what they actually get to learn in graduate school. Second, the book is valuable for all those who have influence on the content and design of graduate programmes in economics. For all others this can still be a book for the coffee-table, since my own experience has shown that it does function quite well as a conversation starter.

\section{REFERENCES}

Colander, David C. 2007. The making of an economist, redux. Princeton and Oxford: Princeton University Press.

Klamer, Arjo, and David C. Colander. 1990. The making of an economist. Boulder and London: Westview Press.

René L. P. Mahieu is currently a research master student at the Erasmus Institute for Philosophy and Economics, Erasmus University Rotterdam. Contact e-mail: <renemahieu@gmail.com> 